\title{
The Effect Of Speed Reading Instruction On Japanese High School Students' English Reading Comprehension And Vocabulary Development
}

Paul Underwood, Tokai University, Japan

Gordon Myskow, Toyo University, Japan

Takahiko Hattori, Otsuma Women's University, Japan

\begin{abstract}
This study investigated the effects of a six-month course in speed reading in three areas of reading proficiency development: 1) general reading comprehension, 2) knowledge of high-frequency vocabulary, and 3$)$ reading-rate and accuracy. The participants $(N=105)$ were Japanese students studying English as a foreign language in Grade 10 at a Japanese private senior high school, randomly assigned to an experimental group $(n=51)$ which received the speed reading treatment, and a control group $(n=54)$ which received supplementary activities focused on high-frequency vocabulary development. The findings indicated that both the experimental and control groups made significant improvements in general reading comprehension. However, there was no significant difference between the experimental group $(M=14.27, S D=4.01)$ and the control group $(M=14.31, S D=4.07) ; t(103)=-.051, p=.959$. Both the experimental group $(M=1.29$, $S D=2.52)$ and the control group $(M=1.35, S D=2.49)$ increased their knowledge of highfrequency vocabulary. However, again there was no significant difference between the experimental group $(M=25.78, S D=2.96)$ and the control group $M=25.61, S D=2.24 ; t(103)$ $=-.337, p=.737$. In terms of reading-rate development, the findings indicated a significant increase $(M=47, S D=41.99) t(50)=8.01, p<.0005$. Finally, while higher levels of general reading comprehension and high reading speeds were correlated, the relationship was small, $r=.19, n=51$. The range of findings emerging from this current study adds weight to the existing research and goes beyond those conducted in the Japanese context to date. One of the important questions these findings raise relates to the greater influence that other variables, such as lexicogrammatical knowledge, might have on the development of reading comprehension at this level of language proficiency.
\end{abstract}

Keywords: English as Foreign Language; Japanese Secondary School Curriculum; MEXT Policy; Reading Rate; Speed Reading; Vocabulary

\section{INTRODUCTION}

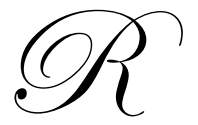

eading is perhaps one of the most intensively researched areas in language learning. Over the past few decades, various attempts have been made to synthesise this research into 'models' of reading that aim to explain "what reading involves, and... how reading works" (Grabe, 2009, p. 83). One such model describes the development of reading proficiency in a foreign language as consisting of three general areas: word recognition, fluency (reading rate), and problem-solving comprehension ability (Carver, 1992, as cited in Alderson, 2003). Expanding on this definition, Grabe (2009) offers the following six components of reading proficiency: 1) word recognition and knowledge of vocabulary, 2) grammatical knowledge, 3) discourse structure knowledge, 4) metacognitive knowledge, 5) content/world knowledge, and 6) cognitive ability (inference, synthesis, and evaluation). 
However, in the Japanese EFL context, research has shown that for the vast majority of senior high school students, English reading has long been limited to translating passages word by word into Japanese, parsing sentences, and then reordering the text to conform to the Japanese language system (e.g., Gorsuch, 1999; Januzzi, 1994; Law, 1994; Yoshida, Fujita, Watanabe, Mori, Suzuki, \& Osada, 2004; Yoshida, Negishi, Watanabe, Naganuma, \& Benesse, 2004). This approach to reading is concerned primarily with developing discrete-point knowledge of language and is characterized predominantly by the use of grammar-translation methodology (Guest, 2000). While the role of grammatical knowledge, the second component of Grabe's (2009) model of reading presented above, is no doubt an essential element in the process of learning to read, the treatment of linguistic structure alone is not conducive to the development of other key areas of reading proficiency, including word recognition and knowledge of vocabulary, both of which are essential to the development of reading fluency.

Perhaps in an effort to promote a more balanced approach to reading instruction, recent changes to the Japanese national curriculum for English (the Course of Study 2009 for Foreign Language, hereinafter, COS 2009) emphasize the role of reading "rapidly" (MEXT, 2009, p. 16) and developing a sufficient command of vocabulary to enable "guessing at the meaning of unknown words" (p. 17-18). But despite these changes to the curriculum, there is little cause for optimism that these changes will have a significant impact on the way reading is taught. One factorof many - that Japanese teachers of English have frequently cited as an impediment to their adoption of policyoriented teaching is a lack of classroom and curricular time resulting from the need to prepare students for university entrance examinations which they believe to contain mostly grammar and translation questions (e.g., Cook, 2009; Gorsuch, 2001; O'Donnell, 2005; Sato \& Kleinsasser, 2004; Underwood, 2011; Underwood \& Hattori, 2011). Few studies in Japan have investigated the degree to which activities devoted to developing rapid reading could be effectively incorporated into the senior high school curricula (cf. Atkins, 2009; Crawford, 2008; Utsu, 2004, 2005 for research at the university level) or the potential benefits of these activities on general reading comprehension.

This study describes one initiative to integrate a speed reading program into a normal reading course at the senior high school level. The article examines specifically the impact that a course in speed reading might have on three areas of reading proficiency: 1) general reading comprehension, 2) knowledge of high-frequency vocabulary, and 3 ) reading-rate development.

\section{BACKGROUND}

\section{The Role Of Word Recognition And Vocabulary Knowledge In Reading Fluency}

Alderson (2003) defines serial models of reading as bottom-up approaches "where the reader begins with the printed word, recognises graphic stimuli, decodes them to sound, and recognises words and decodes meanings" (p. 16). In other words, both word recognition (i.e., orthographic and phonological knowledge) and subsequent decoding of its meaning (i.e., vocabulary knowledge) are necessary components in reading comprehension. Indeed, Grabe (2009) states that a recurrent theme throughout the various models of reading is that vocabulary knowledge and automaticity in word recognition has important instructional implications for the development of reading comprehension.

In relation to the first point, vocabulary knowledge, Alderson (2003) states that

measures of readers' vocabulary knowledge routinely correlate highly with measures of reading comprehension, and are often, indeed, the single best predictor of text comprehension... Research by Laufer (1989) and Liu and Nation (1985) shows that readers need to know 95\% of the words in text to gain adequate comprehension and to be able to guess unknown words from context. (pp. 35-36)

Similarly, Koda (2005) observes that

to understand written texts, learners must have adequate vocabulary, but to build adequate vocabulary, they must have sufficient reading ability to use context [in the absence of other devices] as a clue to new words. The prevalent instructional approach is to equip learners with a core of vocabulary of roughly 2000 highfrequency words in the target language. (pp. 35-36) 
Koda is referring here to West's (1953) General Service List which consists of 2000 of the most highfrequency words in the English language. The significance of this corpus has been confirmed by numerous empirical studies. Nation (2001) in his exhaustive treatment of learning vocabulary in a foreign language shows that across a variety of text types (conversational, fiction, news, and academic) coverage of this list accounts for between 80-90\% according to the text type.

Other research has also demonstrated that $\mathrm{L} 2$ readers with automatic recognition of the most common English words exhibit a higher level of reading comprehension (Grabe \& Stoller, 2002; Pressley, 1998) since less time is spent decoding individual words and working memory can be devoted to higher order processing of texts. In relation to the second point above, word recognition, and developing automaticity is important for Japanese EFL students whose first language orthography and phonology differs significantly from that of the English language. Segalowitz, Poulsen, and Komoda (1991) showed that even for advanced second language learners, the reading process could be slow and difficult, a finding which they concluded was related to poor word-recognition skills rather than a deficiency in knowledge of vocabulary. Alderson (2003) suggests that a lack of such automaticity could consume the necessary resources required to engage in higher level reading processes such as understanding the propositional value of a text, integrating new information with background knowledge, or making inferences - in other words, general reading comprehension.

\section{The Role Of Reading Fluency In The Japanese Senior High School Context}

The preceding discussion highlights how two factors, word recognition and knowledge of vocabulary, are central in determining the fluency with which a student can read. Wolf and Katzir-Cohen (2001) define reading fluency as the "level of accuracy and rate where decoding is relatively effortless... and where attention can be allocated to comprehension" (p. 219). While there are several approaches that have been suggested to facilitate such development, namely extensive reading, repeated reading, and speed reading (see Crawford, 2008, for a discussion of these approaches in the Japanese and first language, L1, contexts), this current paper will confine its discussion to the role of speed reading. This classroom activity is intended to improve reading rate (fluency) while maintaining a high level of comprehension (accuracy) by developing automatic word-recognition skills and consolidating knowledge of vocabulary. This could certainly be beneficial for preparing students for university entrance examinations. Despite many Japanese teachers' frequent claims to the contrary (refer to the Introduction), recent empirical research suggests (Seki et al., 2011; Underwood, 2011, 2010) many entrance exams in Japan now require a broad range of reading and cognitive abilities skills to demonstrate accurate comprehension of a substantial amount of text in a limited period of time.

The importance of reading fluency to the development of general reading proficiency is now highlighted in changes to Japan's national curriculum for English, the COS 2009. The following extract is taken from the Ministry of Education, Culture, Sports, Science, and Technology's (hereinafter, MEXT) Communication English 2, fourskills general English course, which states students should develop proficiency in "reading explanations, critiques, stories and essays rapidly or intensively depending on reading goals...[and] utilizing background knowledge and guessing at the meanings of unknown words when listening and reading" (MEXT, 2009, pp. 16-18, authors' translation).

While this is not the only reference in the COS 2009 as to how reading should be taught, the first part indicates a clear focus on reading fluency in terms of reading rate. This is further illustrated later in the curriculum document by MEXT's detailed and explicit reference to the activity of 'speed reading' (MEXT, 2009, p. 61). The second part of the extract above implies the importance of a sufficient knowledge of high-frequency vocabulary in order for students to deduce from context the meaning of unknown vocabulary. While MEXT has suggested significant increases in the number of words that students are expected to learn across all of its new English courses (MEXT, 2009, p. 92), the basis for the selection of this vocabulary has not been specified. Nonetheless, as the discussion in The Role of Word Recognition and Vocabulary Knowledge in Reading Fluency section suggested, in relation to the amount and nature of vocabulary necessary to understand words from context, it is clear that knowledge of high-frequency vocabulary and word recognition are central in the lower processes of reading comprehension, and development of this knowledge and ability should be encouraged in the classroom. It might also be hypothesized, then, that under timed conditions, the reading of texts controlled for high-frequency vocabulary can lead to greater automatic recognition and increases in general reading comprehension. 


\section{Research Purpose And Questions}

As indicated in the introduction of this paper, this study sought to investigate the impact that a course in speed reading might have on three areas of reading proficiency: 1) general reading comprehension, 2) knowledge of high-frequency vocabulary, and 3) reading-rate development. It also sought to establish the degree to which a specified amount and duration of speed reading could be effectively integrated (effectively defined in terms of student improvement) into a normal course of reading instruction at the senior high school level in Japan. In this way it attempted to understand the extent to which the new COS 2009's objective for reading fluency might be achievable at the classroom level. Accordingly, the following research questions were posed:

1. Do students who receive speed reading instruction improve their general reading comprehension more than students who do not receive such instruction?

2. Do students who receive speed reading instruction improve their knowledge of high-frequency vocabulary more than students who receive only vocabulary instruction?

3. Do students who receive speed reading instruction improve their reading rate while maintaining accuracy in comprehension?

4. Is there a correlation between general reading comprehension and reading speed?

\section{METHODOLOGY}

\section{Participants And Sampling}

Participants were Japanese senior high school first-year (Grade 10) students $(N=105)$ studying at a private school in a central location in Tokyo. The school is ranked as slightly below average in terms of its standardised rank score (hensachi in Japanese), which in Japan is used to rank schools according to the difficulty of their entrance examinations. A comprehensive sample of students was selected for participation in the study. (By enrolling in the English course, they were considered to have self-selected themselves for the study.) Participants were randomly assigned to an experimental group, $n=51$, and a control group, $n=54$. To help reduce sample bias and further ensure that the sample was representative of the population of senior high school students (thereby providing external validity), all returnee and particularly advanced level students were assigned (as per normal) to the advanced English class, and they did not participate in the research.

The teachers participating in the study $(N=4)$ were all non-Japanese nationals who spoke English as their first language. Two of the teachers in the study were novice teachers who were new to the school that year but had some experience working in other schools. The other two were senior teachers who had been teaching in the school for two years. All teachers were familiar with speed reading activities and high-frequency vocabulary study. Table 1 provides details on the assignment of participants and teachers to groups.

Table 1: An Overview of Participants and Teachers to Control and Experimental Groups

\begin{tabular}{lcc}
\hline Control and Experimental Groups & Teachers $(\boldsymbol{N}=\mathbf{4})$ & No. of Students $(\boldsymbol{N}=\mathbf{1 0 5})$ \\
\hline Experimental 1 & Novice A & 18 \\
Experimental 2 & Novice B & 17 \\
Experimental 3 & Senior A & 16 \\
Control 1 & Novice A & 15 \\
Control 2 & Novice B & 13 \\
Control 3 & Senior B & 26 \\
\hline
\end{tabular}

Note. Novice teachers A and B represent the same teachers, that is, they taught in both the control and experimental groups; Senior teacher A taught in only the experimental group and senior teacher B taught in only the control group.

The researchers were not participant teachers in the study, but two of them were teaching at the school, one of whom, the lead researcher, was responsible for overseeing the weekly management of the study. 


\section{Materials}

The course textbook for the experimental group was Reading for Speed and Fluency, 1 (Nation \& Malarcher, 2007). The book comprises eight units of study, starting with vocabulary previewing exercises that are designed to activate schema and provide background knowledge and preview content-specific vocabulary that is not contained in West's (1953) General Service List 2000 (hereinafter, GSL), which was referred to previously. Each of the eight units contains five thematic readings of approximately 300 words. The frequency of vocabulary in the readings is between $87-96 \%$ GSL 1-1000, 2-8\% GSL 1000-2000, 1-5\% Academic Word List (hereinafter, AWL; Coxhead, 2000), and 1-7\% comprising off-list words, that is words not in the GSL. The GSL 2000 and AWL frequency of the vocabulary contained in the questions is also above 90 percent. Five multiple-choice questions ( 3 options) follow each reading and focus broadly on main ideas, details, and occasionally the understanding of vocabulary from context. The control group was provided with West's (1953) GSL 1000 word list, upon which classroom activities were based.

\section{The Research Design And Variables}

The dependent variable was general reading ability and the independent variable was a speed reading treatment. The participants were divided into an experimental and control group, each group consisting of three classes. The experimental group received the speed reading treatment, and the control group received a supplementary vocabulary treatment. This was intended to strengthen the design by ensuring that both groups were receiving equal exposure to high-frequency vocabulary, and, therefore, any gains made by the experimental group might be more easily attributed to the effect of speed reading (P. Nation, personal communication, January 28 , 2008). Thus, the design appeared as

Experimental: A + B, where A represents the experimental group and B the speed-reading treatment.

Control: $\mathrm{A}+\mathrm{C}$, where $\mathrm{A}$ represents the control group and $\mathrm{C}$ the supplementary vocabulary treatment.

\section{Other Variables}

Numerous variables were identified as potential threats to the research. Two intervening variables were identified as student learning styles and extra-curricular learning and study. For the most part, the remaining variables were controlled and are as follows:

- $\quad$ Returnee Or And Advanced-Level Students: The effects of this intervening variable were controlled by removing these students from the research.

- $\quad$ Prior Reading Achievement: The effect of this moderator variable was controlled via the comprehensive self-selected and random nature of the sampling.

- $\quad$ Reading Threshold: An analysis of vocabulary contained in two of the three most popular junior high school textbooks at the time this study was conducted (New Crown 3 and New Horizon 3) indicated that these textbooks provide students with approximately 87\% coverage of West's (1953) GSL 1000 and about 4\% of the GSL 2000 list. The Flesch Reading Ease level is approximately 73\% and the Flesch-Kincaid grade-level is approximately Grade 5. Recalling the level of Reading for Speed and Fluency 1 described in the Materials section, it can be see that the levels are comparable, in terms of the measures here, to textbooks commonly used in junior high schools.

- $\quad$ Increased Exposure To Reading In The Experimental Group: The control group receives less reading per week than the experimental group, which could mean that any gains in general reading ability might not be attributable to speeding reading itself, rather simply having more exposure to reading, whatever kind that may be. Therefore, the effects of this intervening variable were controlled by establishing (via GSL 2000, AWL, Flesch-Kincaid readability, and Flesch-Kincaid grade-level analyses) that Reading for Speed and Fluency, 1 is comparable to the junior high school third year (Grade 9) reading texts, New Crown 3 and New Horizon 3. We can, therefore, claim that the speed reading texts will not likely provide, in principle, any significant and additional learning advantage for the experimental participants in terms of new vocabulary and grammar, rather, any positive increase in general reading proficiency will be attributable to the process of speed reading. 
- $\quad$ Teaching Style: While we acknowledge that the effects of this intervening variable are difficult to control, by standardising the instructional procedures for speed reading activities we are able to claim some degree of control. Additionally, teachers were teaching to a common unified syllabus, using identical materials across the reading, writing and oral syllabus in the rest of the programme. Furthermore, teachers were considered to be quite collaborative, and at a similar level in teaching qualification, expertise, and experience. They also met regularly throughout the week to discuss and plan lessons together.

- $\quad$ Motivation For And Attitude Towards Reading: Students entering the English course do not do so for the purpose of focusing specifically on reading and study all four macro-skills as part of their required course. They can therefore be considered to have normal levels of motivation.

- $\quad$ Gender: The effects of this organismic variable have been negated by the natural balance of male and female students in each homeroom.

- $\quad$ Discussion Between Control And Experimental Group Students Regarding The Different Experiences Of Reading In Their Classes: The effects of this intervening variable were reduced by ensuring that when homerooms were divided between teachers, the homerooms did not consist of control and experimental groups.

\section{Definition Of Terms}

General reading comprehension, as measured in the 45-minute pre- and post-course test of general reading comprehension, is operationally defined as responding correctly to at least $80 \%$ of the four option 24 multiplechoice items (or 19 out of 24 items) based on three kinds of texts: fiction (pedagogic); academic (adjusted authentic); and academic (pedagogic). Pre- and post-course general reading comprehension test items assessed reading ability in the following areas:

- $\quad$ Main ideas at the paragraph and passage level

- Details at both the 'local' level and more 'globally' across the text (Bensoussan, Goldenblatt, \& Kreindler, 1984), requiring recognition of exact-word matching and synonymy in the questions and answer in the text

- Inference at local and global level of the text

- $\quad$ Prediction

- Understanding vocabulary from context

- $\quad$ Understanding metaphoric use of language

- $\quad$ Cohesion (i.e., anaphoric reference, cause and effect, and best-fit sentence and clause)

- $\quad$ Recognising genre

Speed Reading is operationally defined as follows:

- $\quad$ Reading as quickly as possible while maintaining a high level of comprehension. Once students had read the passage carefully and recorded their reading speed, they were not permitted to refer back to the text while answering the comprehension questions.

- $\quad$ Comprehension refers to the understanding of main ideas and details, which is measured by five multiplechoice response questions (containing 3 options), which focus broadly on main ideas, details, and occasionally the understanding of vocabulary from context.

- $\quad$ A high level refers to responding correctly to at least four out of the five questions (80\%).

\section{Procedures}

The research was conducted between April and July, breaking for the six-week summer recess, and continuing from September to December. At the beginning of the course, entry data was collected from three sources: on day one, a GSL 1000 vocabulary test and a test of general reading comprehension; and after three classes, the times and comprehension scores for the first three speed readings from student textbooks.

During the course, both control and experimental groups received two fifty-minute English reading classes weekly. During this time the experimental group completed one speed reading in each class, which was conducted in 
the first ten minutes. For the control group, in place of speed reading, participants received twice-weekly activities that practiced high-frequency vocabulary, the duration of which was the same as the time spent on speed reading in the experimental group. All subsequent study was the same for both experimental and control groups.

Weekly meetings were held to maintain project cohesion, plan lessons, and address questions teachers had regarding their lessons. This also enabled the lead researcher to monitor the study closely.

At the end of the course, exit data was collected from the three sources detailed above. Regarding the general reading comprehension tests, due to the nine-month gap occurring between the administration of the pre-test and the post-test, the same tests were used for both administrations. The main advantage of using just one test was that creating two different tests that were comparable in terms of item-difficulty, vocabulary level, and other textual features — and, importantly, establishing this through statistical consistency checks—would not be required.

\section{Data Analysis}

SPSS software (Version 18) was used to input and analyze data. The data set was examined and participants missing data and other outliers were removed from the final analysis. As the final sample sizes for both the experimental and control group were more than 30 (experimental, $n=51$ and control, $n=54$ ) normality was assumed (Pallant, 2007).

\section{Establishing The Reliability Of The General Reading Comprehension Pre-And Post-Test}

A pilot version of the general reading comprehension test was administered to a highly comparable sample of Grade 5 students $(N=100)$ in the academic year prior to the current study. The data from the pilot administration was used to determine the degree to which the test separated high and low scoring students. Using the KuderRichardson 20 formula, a high reliability coefficient of 0.99 was observed. Additionally, an item analysis of individual distracters was conducted in order to assess their performance. While one minor adjustment was made, no other significant concerns were identified. In summary, the checks indicated that the test was able to differentiate clearly between different levels of students and the items were operating effectively. The test was, therefore, considered to be a reliable measure of reading ability.

In addition to the measures described above, the test was created to ensure that it was at a comparable level to the passages contained in Reading for Speed and Fluency 1. The following levels were established: highfrequency vocabulary, GSL 1000, 86\%; GSL 2000, 7\%; and AWL 1\%; Flesch Reading Ease, 77\%; and FleschKincaid grade-level six. Additionally, thematic content, test length (approximately 950 words) and other textual features (e.g., idiomatic use of language and grammatical complexity) were considered.

\section{Analysis Of The General Reading Comprehension, Reading Speed And Accuracy, And Vocabulary}

Paired-samples $t$-tests were performed to establish whether any post-test gain scores made by the experimental and control groups were significant. Further, independent-samples, $t$-tests were performed to compare the pre- and post-test gain scores of the experimental and control groups in order to establish whether any differences between the two groups were statistically significant. Where the $F$ value indicated the gain difference in means was statistically significant, effect size was calculated via the Eta squared formula to determine the degree of importance. The magnitude was interpreted as small effect $=.01$, moderate effect $=.06$, and large effect $=.14$ (Cohen, 1988). Alpha levels were set at $\mathrm{p}<.05$. In addition, Levene's test was also performed to confirm homogeneity of variance prior to interpreting the independent-sample $t$-tests.

Regarding the data collection and pre-analysis of the reading speed and accuracy of comprehension, the times and comprehension scores for the first and last three speed readings were taken from student textbooks, and the mean gain score was calculated (Chung \& Nation, 2006). 
Analysis Of The General Reading Comprehension, Reading Speed And Accuracy, And Vocabulary

For Research Question 4, Pearson product-moment correlation analyses were conducted to explore whether students who scored highly on the general reading comprehension post-test were also fast readers. The strength of the relationship between these variables was interpreted as: small, $\mathrm{r}=.10$ to .29 ; moderate, $\mathrm{r}=.30$ to .49 ; and large, $\mathrm{r}=.50$ to 1.0 (Cohen, 1988).

\section{FINDINGS}

\section{Research Question 1}

Research Question 1 sought to investigate whether students who received speed reading instruction could improve their general reading comprehension more than students who do not receive such instruction. Firstly, paired-samples $t$-tests were performed to establish whether any post-test gain scores made by the experimental and control groups were significant. The findings are presented in Tables 2 and 3.

Table 2: Paired-samples $t$-test of Raw Score* Performance of the Experimental Group on General Comprehension Pre- and Post-course Tests

\begin{tabular}{lccccc}
\hline & $\boldsymbol{M}$ & $\boldsymbol{S D}$ & $\boldsymbol{d}$ & $\boldsymbol{t}$ & Effect Size $^{\text {a }}$ \\
\hline Pre-test & 12.37 & 3.99 & 50 & $-3.43 * *$ & .19 \\
Post-test & 14.27 & 4.00 & 50 & & \\
\hline
\end{tabular}

* Maximum possible score $=30$

$* * \mathrm{p}<.001$.

${ }^{\mathrm{a}}$ Eta squared.

The results presented in Table 2 indicate there was a statistically significant increase in post-test means $(M$ $=1.9, S D=3.96) t(50)=-3.43, p<.001$ (two-tailed). The mean increase in raw scores was 1.9 with a $95 \%$ confidence interval ranging from -3.02 to -0.79 . The magnitude of the difference was large (eta squared $=.19$ ), indicating that the results are significant and meaningful.

Table 3: Paired-samples $t$-Test of Raw Score* Performance of the Control Group on General Comprehension Pre- and Post-Course Tests

\begin{tabular}{lccccc}
\hline & $\boldsymbol{M}$ & $\boldsymbol{S D}$ & $\boldsymbol{d f}$ & $\boldsymbol{t}$ & Effect Size $^{\text {a }}$ \\
\hline Pre-test & 11.48 & 3.85 & 53 & $-5.32 * *$ & .35 \\
Post-test & 14.31 & 4.07 & 53 & & \\
\hline
\end{tabular}

* Maximum possible score $=30$

$* * \mathrm{p}<.0005$.

${ }^{\mathrm{a}}$ Eta squared.

The results presented in Table 3 indicate there was a statistically significant increase in post-test means $(M$ $=2.8, S D=3.91) t(53)=-5.32, p<.0005$ (two-tailed). The mean increase in raw scores was 2.8 with a $95 \%$ confidence interval ranging from -3.09 to -1.77 . The magnitude of the difference was particularly large (eta squared $=.35$ ), indicating that the results are significant and meaningful.

Second, independent-samples, $t$-tests were performed to compare post-test gain scores of the experimental and control groups in order to establish whether any differences between the two groups were statistically significant. Levene's test confirmed that equal variance could be assumed (.98), and the output data was interpreted accordingly. The findings are presented in Table 4. 
Table 4: Independent-samples $t$-test of the Raw Score*

Difference between the Control and Experimental Groups on General Comprehension Post-course Tests

\begin{tabular}{lcccc}
\hline Group & $\boldsymbol{M}$ & $\boldsymbol{S D}$ & $\mathbf{N}$ & Sig. (2-tailed) \\
\hline Experimental & 14.27 & 4.01 & 51 & .959 \\
Control & 14.31 & 4.07 & 54 & \\
\hline
\end{tabular}

* Maximum possible score $=30$

The results presented in Table 4 indicate that in terms of improvements in general reading ability, there was no statistically significant difference between the post-test means of the experimental group $(M=14.27, S D=4.01)$ and control group $M=14.31, S D=4.07 ; t(103)=-.051, p=.959$ (two-tailed).

\section{Research Question 2}

Both the experimental group $(M=1.29, S D=2.52)$ and control group $(M=1.35, S D=2.49)$ improved their knowledge of GSL 1000 vocabulary as measured by the pre- and post-tests. However, the second research question was concerned with whether students who receive speed reading instruction controlled for high-frequency vocabulary could improve their knowledge of high-frequency vocabulary more than students who receive only explicit vocabulary instruction. Independent-samples, $t$-tests were performed to compare post-test gain scores of the experimental and control groups in order to establish whether any differences between the two groups were statistically significant. Once again, Levene's test confirmed that equal variance could be assumed (.74), and the output data was interpreted accordingly. The findings are presented in Table 5.

Table 5: Independent-samples $t$-test of the Raw Score*

Difference between the Control and Experimental Groups on GSL Vocabulary Post-course Tests

\begin{tabular}{lllll}
\hline Group & $\boldsymbol{M}$ & $\boldsymbol{S D}$ & $\mathbf{N}$ & Sig. (2-tailed) \\
\hline Experimental & 25.78 & 2.96 & 51 & .737 \\
Control & 25.61 & 2.24 & 54 & \\
\hline
\end{tabular}

Note. GSL $=$ General Service List 1000

* Maximum possible score $=30$

The results presented in Table 5 indicate that in terms of improvements in high-frequency GSL 1000 vocabulary there was no statistically significant difference between the post-test means of the experimental group $(M=25.78, S D=2.96)$ and control group $M=25.61, S D=2.24 ; t(103)=-.337, p=.737$ (two-tailed).

\section{Research Question 3}

The third research question explored whether student who receive speed reading instruction can improve their reading rate while maintaining accuracy in comprehension. A paired-sample $t$-test was performed to establish whether any post-test gain scores were statistically significant. The results presented in Table 6 indicate there was a statistically significant increase in post-test means $(M=47$ [0:47], $S D=41.99$ [0:42] $t(50)=8.01, p<.0005$ (twotailed). The mean increase in speed was 47 seconds with a 95\% confidence interval ranging from 35.23 to 58.89 . The magnitude of the difference was particularly large (eta squared $=.56$ ), indicating that the results are significant and meaningful.

Descriptive statistics indicated that students comprehension remained constant between the start of the course and the end of the course $(M=3.2, S D=.84)$. 
Table 6: Paired-samples $t$-test of the Experimental Group's Performance on Reading Speed* in the First and Last Three Speed Readings

\begin{tabular}{lccccc}
\hline Reading & $\boldsymbol{M}$ & $\boldsymbol{S D}$ & $\boldsymbol{d}$ & $\boldsymbol{t}$ & Effect Size $^{\text {a }}$ \\
\hline First three readings & $173(2: 53)$ & 37.41 & 50 & $8.01 * *$ & .56 \\
Last three readings & $125(2: 05)$ & 38.55 & 50 & & \\
\hline
\end{tabular}

* Speed is recorded in seconds; the numbers in brackets represents minutes and seconds

$* * \mathrm{p}<.0005$.

${ }^{\mathrm{a}}$ Eta squared.

\section{Research Question 4}

Research question 4 sought to examine whether there is a correlation between general reading ability and reading speed. To answer this, Pearson product-moment correlation analyses were conducted. The findings are presented in Table 7.

Table 7: Pearson Product-moment Correlation of General Reading Comprehension and Reading Speed* Performance

\begin{tabular}{|c|c|c|c|}
\hline & & $\begin{array}{c}\text { General Reading } \\
\text { Comprehension }\end{array}$ & $\begin{array}{c}\text { Reading } \\
\text { Speed }\end{array}$ \\
\hline \multirow{3}{*}{$\begin{array}{l}\text { General } \\
\text { Comprehension }\end{array}$} & Pearson Correlation & 1 & -.192 \\
\hline & Sig. (2-tailed) & & .178 \\
\hline & $\mathrm{N}$ & 51 & 51 \\
\hline \multirow[t]{3}{*}{ Reading Speed } & Pearson Correlation & -.192 & 1 \\
\hline & Sig. (2-tailed) & .178 & \\
\hline & $\mathrm{N}$ & 51 & 51 \\
\hline
\end{tabular}

* Speed was input in seconds

The results in Table 7 indicate that while general reading comprehension and reading speed were correlated (the negative sign indicating that high scores on general reading comprehension are associated with high reading speeds), the relationship was a small, $r=.19, n=51$. In other words, students scoring highly on the general reading comprehension test were not always able to demonstrate faster reading.

\section{DISCUSSION AND CONCLUSIONS}

The first and second research questions sought to explore whether students taking a course of speed reading that was controlled for high-frequency vocabulary would make greater improvements in general reading comprehension and vocabulary acquisition in comparison to students who received only de-contextualised practice in high-frequency vocabulary. The findings clearly indicated that both experimental and control groups' improved on the general reading comprehension and the GSL 1000 post-tests, although there was no discernable difference between the two groups. In other words, improvements in reading comprehension could have resulted from the speed reading treatment given to the experimental group and the explicit vocabulary practice provided to the control group.

What is perhaps important to note here, is that common to both these treatments is the focus on highfrequency vocabulary. Considering the findings related to Research Questions 3 and 4, although students receiving speed reading practice were able to make significant gains in terms of their reading speed (an increase of 47 seconds), the degree of accuracy in answering the comprehension questions following each reading did not improve over the course of study, remaining consistently (3 out of 5 questions correct) below what was operationally defined as an indication of accurate reading (4 out of 5 correct). Regarding Research Question 4, although the current study confirmed that higher comprehension was associated with higher reading speeds, there was only a small relationship between the two variables. Both of these findings add weight to those of Utsu's (2005) longitudinal study of 
university-level students, cited in the introduction to this paper, who found that though reading speeds increased significantly, there were negligible increases in comprehension scores. However, the findings of the current study do not provide any further support for Grabe (2009) and Alderson's (2003) observation, (cited in the Background section) that both knowledge of vocabulary and word recognition are critical in reading comprehension development. While the research in that area is clear, in terms of the participants in the current study, it might well be the case that at this level of language proficiency, instruction which focuses on building greater linguistic ability (e.g., lexico-grammatical competence) could be of more benefit to students. If this were empirically established through further research, it would have important implications for curriculum and policy planning for Grade 10 Japanese senior high school students. Of course, we must also consider alternative means of assessing comprehension accuracy to those adopted in Chung and Nation's 2006 study (i.e., calculating the average of the first and last three reading scores). For instance, a further analysis of students' performance in the first, second, and third ranges (i.e., readings 1-10, 11-20, and 21-30) of their textbook reading comprehension scores might indeed reveal different results.

A further explanation as to why post-speed reading comprehension scores showed no improvement might be related to the amount of time spent on this activity, which could have simply been insufficient in developing the fluency in word-recognition skills required to complete the post-test in general reading comprehension within the 45-minute time limit. Once again, further empirical studies are necessary to clarify the frequency and intensity of timed reading required for such a threshold. Nonetheless, if this were so, the problem arises as to how to provide more curriculum time for such activities. Recalling the research referred to in the introduction to this paper (e.g., Cook, 2009; Gorsuch, 2001; O'Donnell, 2005), Japanese teachers have frequently cited lack of time and space in the curriculum as impediments working against their adoption of policy-oriented practices, such as speed reading. In the absence of any positive change in curriculum conditions, teachers would need to devise creative ways of integrating such instruction with current materials and content (see, for example, Underwood \& Hattori, 2010, on ways to integrate speed reading with MEXT-approved textbooks). Alternatively, teachers could find ways to encourage and develop student autonomy in this and other activities, such as extensive reading, which has also been shown to benefit the reading fluency of Japanese senior high school students (Tanaka \& Stapleton, 2007).

Overall, the findings of this current study add weight to the existing research and perhaps go beyond those conducted in the Japanese context to date. Firstly, to the best of our knowledge there have not been any studies which have isolated the speed reading variable by adopting experimental and control groups comprising a generalisable sample. Secondly, we were also unable to find any empirical studies conducted in the Japanese senior high school context, which have explored the effects of speed reading on the three areas under focus in this study: general reading comprehension, vocabulary development, and reading rate and accuracy. A third and final area in which the current study contributes is related specifically to its findings. First of all, it is clear from the data that senior high school students can make significant gains in reading speed over their course of study. Second, the data further suggests that while reading speed increases significantly, comprehension levels do not improve. Future research should explore this phenomenon by perhaps incorporating the additional variable of linguistic development discussed above.

In summary, we suggest that for the value of MEXT's COS 2009 fluency component to be acknowledged by teachers and implemented in their classrooms, not only more empirical justification for speed reading needs to be established, but also sufficient curriculum time and further consideration of the other context-related impediments working against adoption of such curricular recommendations.

\section{AUTHOR INFORMATION}

Paul R. Underwood is Junior Associate Professor of English at Tokai University, Japan. He is a Ph.D. candidate at Lancaster University (UK) in the Department of Linguistics and English Language. His research interests include EFL Reading and Grammar Teaching, Educational Innovation, Teacher Beliefs, Theory of Planned Behaviour. E-mail: underwood@ tokai-u.jp 
Gordon Myskow is Adjunct Professor of TESOL at Columbia University (Japan) and a Lecturer in the Department of Economics at Toyo University. He is a member of the advisory committee for the United Nations Test of English in Japan. His research interests include Second Language Writing and Genre Analysis. E-mail: gmyskow@gmail.com

Takahiko Hattori, Ph.D., is Professor of Linguistics and Language Research at Otsuma Women's University, Japan. He has published extensively, and made presentations both in Japan and North America related to English Language Education. His research interest includes Second Language Attrition and English Language Instruction. Email: hattori@otsuma.ac.jp. Corresponding author.

\section{REFERENCES}

1. $\quad$ Alderson, J.C. (2003). Assessing reading. Cambridge: Cambridge University Press.

2. Atkins, A. (2010). Timed reading: Increasing reading speed and fluency. In A. M. Stoke (Ed.), JALT 2009

3. $\quad$ Conference Proceedings. Tokyo: JALT.

4. Bensoussan, M., Goldenblatt, L., \& Kreindler, I. (1984). Changing the difficulty level of multiple-choice EFL reading comprehension questions, Language Testing 1, 105-09.

5. Chung, M., \& Nation, I. S. P. (2006). The effect of a speed reading course. English Teaching, 61(4), 181204.

6. Cohen, J. W. (1988). Statistical power analysis for the behavioral sciences $\left(2^{\text {nd }}\right.$ Ed.). Hillsdale, NJ: Lawrence Erlbaum Associates.

7. Cook, M. (2009). Factors inhibiting and facilitating Japanese teachers of English in adopting communicative language teaching methodologies. $K @ T A, 11,99-116$. Retrieved from http://puslit2.petra.ac.id/ejournal/index.php/ing/article/shop/ 17887/17815

8. Coxhead, A. (2000). A new academic word list. TESOL Quarterly, 34(2), 213-238.

9. Crawford, M. J. (2008). Increasing reading rate with timed reading. The Language Teacher, 32(2), 3-7.

10. Gorsuch, G. (1999). Exploring the relationship between educational policy and instruction in Japanese high school EFL classrooms (Doctoral dissertation). Available from ProQuest Dissertations and Theses database. (UMI No. 9938669)

11. Gorsuch, G. (2001). Japanese EFL teachers' perceptions of communicative, audiolingual, and yakudoku activities: The plan versus reality. Educational Policy Analysis Archives, 9. Retrieved from http://epaa.asu.edu/ojs/article/view/339/465

12. Grabe, W. (2009). Reading in a second language: Moving from theory to practice. Cambridge: Cambridge University Press.

13. Grabe, W., \& Stoller, F. L. (2002). Teaching and researching reading. Harlow: Pearson Education Ltd.

14. Guest, M. (2000). But I have to teach grammar!. The Language Teacher, 24(11), 23-29.

15. Januzzi, C. (1994). Team teaching in the reading class. In M. Wada and T. Cominos (Eds.), Studies in team teaching (pp. 119-131). Tokyo: Kenkyusha.

16. Koda, K. (2005). Insights into second language reading. Cambridge: Cambridge University Press.

17. Law, G. (1994). College entrance exams and team teaching in high school English classes. In M. Wada and T. Cominos (Eds.), Studies in team teaching (pp. 90-102). Tokyo: Kenkyusha.

18. MEXT. (2009). 高校学校学習指導要領説明 : 外国語編 英語編 [The course of study for senior high schools guidelines explanation: Foreign languages (English)]. Retrieved from http://www.mext.go.jp/component/a menu/education/micro detail/_ icsFiles/afieldfile/ 2010/ 01/29/ 1282000 9.pdf

19. Nation, I. S. P. (2001). Learning vocabulary in another language. Cambridge: Cambridge University Press.

20. Nation, P. \& Malarcher, C. (2007). Reading for speed and fluency. Seoul: Compass Publishing.

21. O'Donnell, K. (2005). Japanese secondary English teachers: Negotiation of educational roles in the face of curricular reform. Language, Culture, and Curriculum, 18, 300-315.

22. Pallant, J. (2007). SPSS survival manual. Maidenhead, England: Open University and McGraw-Hill Education.

23. Pressley, M. (1998). Reading instruction that works. New York: Guilford Press.

24. Sato, K., \& Kleinsasser, R. C. (2004). Beliefs, practices, and interactions of teachers in a Japanese high school English department. Teaching and Teacher Education, 20, 797-816. 
25. Segalowitz, N., Poulsen, C., \& Komoda, M. (1991). Lower level components or reading skill in higher level bilinguals: Implications for reading instruction. In J. H. Hulstijin and J. F. Matter (Eds.), Reading in two languages, AILA Review (Vol. 8, pp. 15-30). Amsterdam: Free University Press.

26. Seki, S., Kato, K., Chamoto, T., Nagakura, Y., Miura, T., \& Watari, Y. (2011). 現代の大学入試問題に、 文法訳読式授業どれだけ対応できるか。[To what degree can the grammar-translation classroom cope with contemporary college-entrance English examinations?]. Journal of the Chubu English Language Education Society, 40, 315-322.

27. Tanaka, H., \& Stapleton, T. (2007). Increasing reading input in Japanese high school EFL classrooms: An empirical study exploring the efficacy of extensive reading. The Reading Matrix, 7(1), 115-130.

28. Underwood, P. (2010). A comparative analysis of MEXT English reading textbooks and Japan's National Centre Test. RELC Journal, 41(2), 165-182.

29. Underwood, P. (2011). Teacher beliefs and intentions regarding the instruction of English grammar under national curriculum reforms: A Theory of Planned Behaviour perspective. Manuscript submitted for publication.

30. Underwood, P., \& Hattori, T. (2011). Integrating Policy and Pedagogy: The Theoretical, Contextual, and Practical Considerations for EFL Reading Instruction in Japan. The Japanese Anthropological Linguistic Association's Journal, 6, 9-59.

31. Utsu, M. (2004). Timed readings no riyou to sono kouka [Timed readings and their effects on students]. Bulletin of Yonezawa Women's College of Yamagata Prefecture, 39, 31-37.

32. Utsu, M. (2005). Timed readings no riyou to sono kouka 2 [Timed Readings and their effects on students (Part II)]. Bulletin of Yonezawa Women's College of Yamagata Prefecture, 40, 27-34.

33. West, M. (1953). A general service list of English words. London: Longmans, Green and Co. Ltd.

34. Wolf, M., \& Katzir-Cohen, T. (2001). Reading fluency and its intervention. Scientific Studies of Reading, 5(3), 211-239.

35. Yoshida, K., Fujita, T., Watanabe, Y., Mori, H., Suzuki, S., \& Osada, M. (2004). 中学校・高等学校段階 で求められる英語力の指標に関する研究最終報告 [Research into the expected English ability levels of junior and senior high schools]. Ministry of Education, Culture, Sports, and Science.

36. Yoshida, K., Negishi, M., Watanabe, Y., Naganuma, N., \& Benessee International Department, Kyoiku kiso kenkyubu (2004). 東アジア高校英語教育調查一指導と成果の検証 [Survey of English education in East Asian high schools - verification of instruction and its outcomes]. Benesse Corporation. 


\section{NOTES}

